\title{
Clarithromycin versus Gemifloxacin in Quadruple Therapeutic Regimens for Helicobacter Pylori Infection Eradication
}

\author{
Fariborz Mansour-Ghanaei ${ }^{1}$, Zahra Pedarpour ${ }^{2}$, Afshin Shafaghi ${ }^{3,}$, Farahnaz Joukar $^{4}$
}

1. Professor, Gastrointestinal \& Liver Diseases Research Center (GLDRC), Guilan University of Medical Sciences, Rasht, Iran

2. Researcher, GI Cancers Screening and Prevention Research Center (GCSPRC), Guilan University of Medical Sciences, Rasht, Iran

3. Associate Professor, GI Cancers Screening and Prevention Research Center (GCSPRC), Guilan University of Medical Sciences, Rasht, Iran

4. $\mathrm{PhD}$ by Research student, Faculty member, Gastrointestinal \& Liver Diseases Research Center (GLDRC), Guilan University of Medical Sciences, Rasht, Iran

\section{* Corresponding Author:}

Afshin Shafaghi, MD

Associate Professor, GI Cancers Screening and Prevention Research Center (GC-

SPRC), Guilan University of Medical Sciences, Razi Hospital, Sardar-Jangle Ave., P.O. Box: 41448-95655, Rasht, Iran

Tel: + 981315535116

Fax: + 981315534951

Email: drafshinshafaghi@gmail.com

Received: 05 Dec. 2016

Accepted: 06 Mar. 2017

\section{ABSTRACT}

\section{BACKGROUND}

Helicobacter pylori (H. pylori) infection is a major casual factor in any peptic diseases. Clarithromycin as one of the drugs recommended for the infection eradication regimen has shown different levels of resistance. The present study is comparing the effectiveness of clarithromycin- and gemifloxacin - based quadruple regimens in H. pylori eradication.

\section{METHODS}

This was a prospective double blind randomized clinical trial on patients with clear indication of H. pylori eradication. The patients were randomly divided into two groups: "BPAC group" treated with bismuth subcitrate $(240 \mathrm{mg})$, pantoprazole $(20 \mathrm{mg})$, amoxicillin (1 gr), and clarithromycin (500 mg), all twice daily, and the "BPAG group" treated with bismuth subcitrate, pantoprazole, and amoxicillin with same doses as "BPAC group" and gemifloxacin (320 mg daily) all for 10 days. Three months after the end of therapy, 14C-Urea breath test was performed to confirm the eradication. All the patients were assessed for compliance and drug side effects. Based on per-protocol (PP) and intention-to-treat (ITT) methods, data were analyzed and a $P$ value $<0.05$ was considered as statistically significant. This project has been registered in the Iranian registry of clinical trials (IRCT).

\section{RESULTS}

Three patients were excluded from the survey and finally, 179 patients ( 89 patients in BPAC group and 90 patients in BPAG group) including 71(39.66\%) men with the mean age of $46.4 \pm 12.3$ years completed the treatment period. The incidence of side effects between the two study groups did not differ significantly. The success rate of BPAC regimen eradication was remarkably greater than BPAG regimen (ITT analysis; $89 \%$ vs 77\%, respectively; CI 95\%: 1.072-5.507, $P<0.015$ and PP analysis; $91 \%$ vs $77.8 \%$ respectively; CI $95 \%$ : $P<0.015$ ). There was no significant relationship between the demographic features and the eradication results.

\section{CONCLUSION}

The results showed that gemifloxacin is not a good alternative for clarithromycin in H. pylori eradication regimens in our region.

\section{KEYWORDS:}

Helicobacter pylori infection; Eradication regimens, Clarithromycin, Gemifloxacin.

Please cite this paper as:

Mansour-Ghanaei F, Pedarpour Z, Shafaghi A, Joukar F. Clarithromycin versus Gemifloxacin in Quadruple Therapeutic Regimens for Helicobacter Pylori Infection Eradication. Middle East J Dig Dis 2017;9:100-106. DOI: 10.15171/mejdd.2017.58.

\section{INTRODUCTION}

On the basis of the fact that there is a wide range of Helicobacter pylori ( $\mathrm{H}$. pylori) infection prevalence rate among the world's populations $(50-70 \%)^{1}$, it seems that it is the most common human infection worldwide. Also, some 
epidemiological surveys have reported that the infection has affected about $20-50 \%$ of the population in Western countries and up to $80 \%$ in developing countries. ${ }^{2,3}$

Currently, the strong relationship between $\mathrm{H}$. pylori infection and chronic gastritis, peptic ulcer disease, and gastric cancers is well demonstrated. ${ }^{2-4}$ On the other hand, eradication of the infection is associated with ulcer healing ${ }^{4}$, regression of mucosa associated tissue lymphoma ${ }^{5}$, and decreased cancer risk. ${ }^{6}$ Therefore, the eradication of the pathogen is of great importance to reduce H.pylori related complications.

The most approved $H$. pylori infection eradication regimen, with a success rate of around $80 \%{ }^{7}$, is a quadruple combination of an acid suppressor (usually a proton pump inhibitor), and bismuth subcitrate with two antibiotics (amoxicillin, metronidazole, tetracycline, or clarithromycin) ${ }^{8}$

Currently, due to the high level of antimicrobial resistance, patients' poor compliance, and drugs side effects, the treatment failure rate is increasing. ${ }^{9}$ Considering this worldwide problem, there has been a search for an alternative drug that is effective, safe, easy to use, inexpensive, and with a low propensity to induce the development of resistant strains. ${ }^{8,9}$

One of the drugs that show such a high level of resistance is clarithromycin. ${ }^{9}$ In a recent study, Camargo and colleagues ${ }^{10}$, reported $12 \%$ resistance for clarithromycin. Also, some Iranian surveys such as those performed by Farshad $^{11}$, Abadi $^{12}$, and their colleagues showed a resistance rate of $5-45.2 \%$ for this macrolid. Based on these findings and the fact that Iran is one of the developing countries with high prevalence of $H$. pylori infection $(83.5 \%)^{13}$, the importance of $H$. pylori eradication and replacing clarithromycin with other antibiotics becomes more evident.

The present study is evaluating the H. pylori eradication rate of gemifloxacin in comparison with clarithromycin in quadruple regimen combined with bismuth subcitrate, pantoprazole, and amoxicillin.

\section{MATERIALS AND METHODS}

This was a prospective double blind randomized clinical trial, designed by Gastrointestinal and Liver Diseases Research Center of Guilan University of Medical Sciences, in Rasht the capital of Guilan province, northern Iran, from October 2013 to August 2014.
We included the consecutive patients (aged between 18 to 80 years) with dyspepsia and no history of previous $H$. pylori treatment, referred to internal medicine and gastroenterology clinics. If the presence of $\mathrm{H}$. pylori infection was established and there was a clear indication for the eradication therapy, the patient would be enrolled to the study. H. pylori infection defined as positive 14C-Urea breath test (UBT) or positive pathology of the endoscopic biopsy samples. The samples were analyzed by a pathologist who was blind to the study protocol. Dyspepsia is a general term that refers to symptoms originating from the upper gastrointestinal tract. As such, it may encompass a variety of symptoms. Typically, the affected patients describe epigastric pain but may also complain of heartburn, nausea, vomiting, abdominal distention, heartburn, early satiety, and anorexia. ${ }^{14}$

Exclusion criteria: Pregnant and breast feeding women, and patients with gastric and esophageal malignancies or surgeries, pyloric stenosis, liver cirrhosis, opium addiction, consumption of cholestyramine, chronic renal failure, congestive heart failure, history of seizure and hematologic disorders were excluded from the study.

Study protocol: At the first step, the demographic features were recorded and then all the patients were randomly divided into two groups. Randomization was done using the simple randomization method. The two study groups were: "BPAC group" $(\mathrm{n}=91)$ treated with bismuth subcitrate $240 \mathrm{mg}$, pantoprazole $20 \mathrm{mg}$, amoxicillin $1 \mathrm{gr}$, and clarithromycin $500 \mathrm{mg}$, all twice a day and the "BPAG group" ( $\mathrm{n}=91)$ treated with bismuth subcitrate, pantoprazole, and amoxicillin with the same dose as the first group and gemifloxacin $320 \mathrm{mg}$ daily, all for 10 days.

12 weeks after the end of the treatment, 14C-UBT was performed to confirm the eradication. All the patients were assessed for compliance and side effects. The severity of any side effects was classified as "mild" with no limitation of the usual daily activities, "moderate" with mild limitation, and "severe" with impossible daily activities. Also, compliance was acceptable when over $80 \%$ of the total medications were taken. The patients with severe side effects and no good compliance were excluded from the study. This study was reviewed and approved by the Ethics Committee of Guilan University of Medical Science, and written informed consent was 
Table 1: Comparison of demographic features between the two study groups

\begin{tabular}{|c|c|c|c|c|}
\hline \multicolumn{2}{|c|}{ Demographic features } & \multirow{3}{*}{$\begin{array}{c}\begin{array}{c}\text { BPAG (\%) } \\
\mathbf{n = 9 0}\end{array} \\
31(34.45) \\
59(65.55)\end{array}$} & \multirow{3}{*}{$\begin{array}{c}\begin{array}{c}\text { BPAC (\%) } \\
\mathbf{n}=\mathbf{8 9}\end{array} \\
40(56.3) \\
49(2.05)\end{array}$} & \multirow{3}{*}{$\begin{array}{c}P \text { value } \\
\text { NS }\end{array}$} \\
\hline \multirow{2}{*}{ Gender } & Male & & & \\
\hline & Female & & & \\
\hline \multirow{4}{*}{ Age group } & $20>$ & $1(1.1)$ & $0(0)$ & \multirow{4}{*}{ NS } \\
\hline & $20-39$ & $32(35.56)$ & $31(34.83)$ & \\
\hline & $40-59$ & $47(52.23)$ & $47(52.81)$ & \\
\hline & $60<$ & $10(11.11)$ & $11(12.36)$ & \\
\hline \multirow{2}{*}{ Smoking } & Yes & $8(8.88)$ & $6(6.74)$ & \multirow{2}{*}{ NS } \\
\hline & No & $82(91.12)$ & $83(93.26)$ & \\
\hline \multirow{2}{*}{ NSAIDs usage } & Yes & $29(32.22)$ & $23(25.84)$ & \multirow{2}{*}{ NS } \\
\hline & No & $61(67.78)$ & $66(74.16)$ & \\
\hline Duration of & $<1$ month & $75(83.33)$ & $72(80.9)$ & \multirow{2}{*}{ NS } \\
\hline Symptoms & $>1$ month & $15(16.64)$ & $17(19.1)$ & \\
\hline
\end{tabular}

BPAG: Bismuth subcitrate, Pantoprazole, Amoxicillin, Gemifloxacin; BPAC: Bismuth subcitrate, Pantoprazol, Amoxicillin, Clarythromycin; NSAIDs: Nonsteroidal Anti-Inflammatory Drugs; p- value $<0.05$ considered as statistically significant

obtained from all the participants. Also, this project has been registered in the Iranian registry of clinical trials (IRCT registration number: IRCT201310221155N17).

Statistical analysis: All data were statistically analyzed using SPSS software for windows version 21.0 (SPSS Inc., Chicago, IL, USA). Using Chi-square test, the gender distribution and the efficacy and frequency of side effects were analyzed. Based on per-protocol (PP) and intention-to-treat (ITT) methods, the data were assessed and a $P$ value $<0.05$ was considered as statistically significant.

\section{RESULTS}

Due to severe drug side effects, three patients were excluded from the survey; two patients in BPAC group (a man with severe diarrhea and a woman with severe nausea and vomiting) and one patient in BPAG group (a woman with severe nausea and no compliance). Finally, 179 patients (89 patients in BPAC group and 90 patients in BPAG group) including 71 (39.66\%) men and 108 women (60.34\%) with the mean age of $46.4 \pm 12.3$ years completed the treatment period. Table 1 shows the demographic characteristics of the patients in both study groups.

The incidence of side effects between the two study groups did not differ significantly. The most frequent drug side effect was mild abdominal pain (15 cases in BPAC group vs 14 cases in BPAG group, table 2).
Table 3 shows the success rate of the two regimens based on two analyses; PP and ITT. Both analyses nearly showed similar results. Based on ITT analysis, the eradication rate achieved by the BPAC regimen was remarkably greater than that obtained by BPAG regimen ( $89 \%$ vs $77 \%$, respectively; CI 95\%: 1.072-5.507, OR=2.43, $p<0.015$ ). Also, based on PP analysis, the eradication rate achieved by the BPAC regimen was remarkably greater than that obtained by BPAG regimen ( $91 \%$ vs $77.8 \%$, respectively; CI $95 \%$ : 1.2-6.975, $\mathrm{OR}=2.89, p<0.015$ ). There was no significant relationship between the demographic features and the eradication results.

\section{DISCUSSION}

Currently, the treatment failure of $H$. pylori infection is increasing worldwide and an ideal therapeutic regimen has not yet been identified. ${ }^{15}$ There are several theories for this medical limitation such as antibiotic resistance with changing the bacterial morphology as antibiotic exposure happens from spiral to coccoid appearance, patients' poor compliance, high gastric acidity, high bacterial load, and cytochrome P450 2C19 (CYP2C19) polymorphism. ${ }^{15-17}$

There are several studies declared that clarithromycin is an strong macrolide for H.pylori eradication, but this antibiotic shows a high level of resistant and is expensive and unavailable for every patient especially in some developing countries. ${ }^{17,18}$ A possible cross resistance be- 
Table 2: Drugs side effects

\begin{tabular}{|c|c|c|c|c|c|}
\hline \multirow{2}{*}{$\begin{array}{l}\text { Table } 2 \text { Drugs side effects } \\
\text { Drugs Side Effects }\end{array}$} & \multicolumn{2}{|c|}{$\begin{array}{c}\text { BAPG } \\
\mathrm{n}=90(\%)\end{array}$} & \multicolumn{2}{|c|}{$\begin{array}{c}\text { BAPC } \\
\mathrm{n}=\mathbf{8 9}(\%)\end{array}$} & \multirow[t]{2}{*}{ P value } \\
\hline & Mild & Moderate & Mild & Moderate & \\
\hline Diarrhea & $3(3.33)$ & $9(10)$ & $4(4.5)$ & $3(3.37)$ & NS \\
\hline Nausea & $7(7.77)$ & $6(6.67)$ & $2(2.25)$ & $9(10.11)$ & NS \\
\hline Vomiting & $3(3.33)$ & $0(0)$ & $1(1.12)$ & $3(3.37)$ & NS \\
\hline Heartburn & $10(11.11)$ & $3(3.33)$ & $9(10.11)$ & $0(0)$ & NS \\
\hline Abdominal pain & $8(8.88)$ & $7(7.77)$ & $9(10.11)$ & $5(5.62)$ & NS \\
\hline Loss of appetite & $4(4.45)$ & $3(3.33)$ & $4(4.5)$ & $1(1.12)$ & NS \\
\hline Cramps & $3(3.33)$ & $0(0)$ & $2(2.25)$ & $3(3.37)$ & NS \\
\hline Headache & $4(4.45)$ & $5(5.56)$ & $6(6.75)$ & $4(4.5)$ & NS \\
\hline Dizziness & $4(4.45)$ & $6(6.67)$ & $7(7.86)$ & $5(5.62)$ & NS \\
\hline Back pain & $2(2.22)$ & $2(2.22)$ & $4(4.5)$ & $0(0)$ & NS \\
\hline Dry mouth & $5(5.56)$ & $6(6.67)$ & $7(7.86)$ & $3(3.37)$ & NS \\
\hline
\end{tabular}

CLD, chronic liver disease: EHPVO, extrahepatic portal vein obstruction; ESRD, endstage renal disease; HTN, hypertension; SMA, superior mesenteric artery; IBD, inflammatory bowel disease, NASH, non-alcoholic steatohepatitis; TB, tuberculosis; VA, villous atrophy

Table 3: H. pylori eradication rate based on two analysis method

\begin{tabular}{|c|c|c|c|c|c|c|c|c|}
\hline & \multicolumn{3}{|c|}{ PP Analysis } & \multirow[t]{2}{*}{$P$ value } & \multicolumn{3}{|c|}{ ITT Analysis } & \multirow[t]{2}{*}{ P value } \\
\hline & Eradicated & Not eradicated & Success rate & & Eradicated & Not eradicated & Success rate & \\
\hline BPAC & 81 & 8 & $91 \%$ & 0.015 & 81 & 10 & $89 \%$ & 0.03 \\
\hline BPAC & 70 & 20 & $77.8 \%$ & & 70 & 21 & $77 \%$ & \\
\hline
\end{tabular}

PP: Per Protocol; ITT: Intention to treat; BPAG: Bismuth subcitrate, Pantoprazole, Amoxicillin, Gemifloxacin; BPAC: Bismuth subcitrate, Pantoprazol, Amoxicillin, Clarythromycin; p-value $<0.05$ considered as statistically significant

tween clarithromycin and erythromycin, an antibiotic that has been widely prescribed for various infections in Iran for many years, may partially explain the unexpectedly high resistance rate of clarithromycin. ${ }^{18}$

Fluoroquinolone-containing regimens are of other measures with good results for $H$. pylori infection treatment. One of these antibiotics is gemifloxacin, which inhibits DNA-gyrase and topoisomerase. Gemifloxacin prevents the cellular replication of gram-positive and gram-negative bacteria. ${ }^{19}$

There are a handful of studies in the literature on gemifloxacin, which claimed that in comparison with clarithromycin, gemifloxacin showed a higher treatment success rate in different infections. ${ }^{20-23}$ Here we tried to compare the treatment results of two quadruple regimens based on clarithromycin and gemifloxacin in H.pylori infection eradication. Figure 1 shows a summary of this survey's method and results.

Our results presented a success rate of $77 \%$ for gemifloxacin with the ITT and $89 \%$ with clarithromycin, re- spectively. Clinical success in the PP was $77.8 \%$ with gemifloxacin and 91\% with clarithromycin, respectively. Since the eradication rate of $H$. pylori infection by BPAC regimen was higher than $80 \%$, it can be considered as an effective regimen in eradicating the infection. But, on the other hand, the BPAG regimen failed to achieve the eradication rate of $80 \%$, so it cannot be used as an effective regimen for the eradication of $H$. pylori infection in our geographic region.

Our findings were similar to some other surveys presented the high power of clarithromycin in $H$. pylori infection treatment. ${ }^{18,24,25}$ For example, Fakheri and colleagues ${ }^{18}$, reported an eradication rate of $84 \%$ by ITT analysis for clarithromycin in quadruple therapy regimen. On the other hand, in contrast to our findings, there are several surveys declared that gemifloxacin was an effective antibiotic for $H$. pylori eradication. ${ }^{26-28}$ In a randomized clinical trial, Masoodi and co-workers ${ }^{27}$, presented that gemifloxacin containing regimen was at least as effective as clarithromycin regimen and this new treatment could 


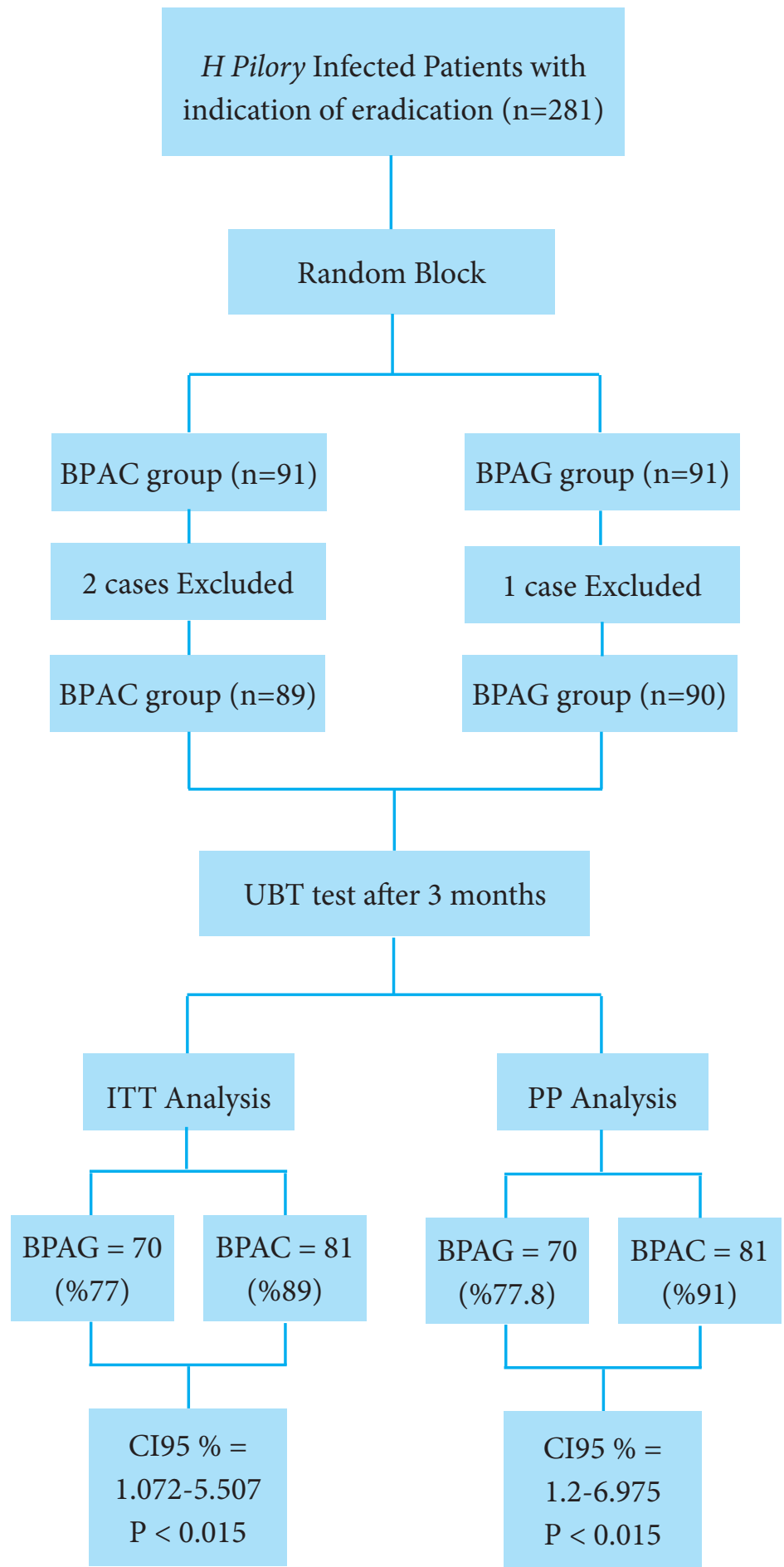

BPAC: Bismuth subcitrate, pantoprazole, amoxicillin, clarithromycin; BPAG: Bismuth subcitrate, pantoprazole, amoxicillin, gemifloxacin; UBT: 14C-Urea breath test; ITT: Intention to treat; PP: Per Protocol

Fig.1: Flow diagram of clarithromycin versus gemifloxacin therapy 
be considered as an alternative for the patients who cannot tolerate clarithromycin. Also, Chang WL and colleagues ${ }^{26}$, concluded that, comparing to fluoroquinolones, gemifloxacin had a more effective anti-bacterial activity on clinical types of H.pylori. In the present study the effect of clarithromycin was lower among the new cases without previous first-line treatment while in our last study ${ }^{3}$, the patients were resistant to clarithromycin. In contrast to our results, in another recent study that was conducted among patients with first-line standard quadruple therapy (clarithromycin-amoxicillin-bismuth-omeprazole) failure, it was revealed that gemifloxacin-containing quadruple therapy provided high H. pylori eradication rate. ${ }^{29}$ It seems that the first-line status of the patients affects the treatment results.

A limitation of our study was the lack of regional estimates of eradication rates with regard to antibiotic resistance. As these studies require personal-based evaluations and the drug resistance rate should be determined in each comparative study the expression of the adverse results obtained in this study highlights the consideration of the other factors such as gastric microbiota in the study population. ${ }^{30}$

Furthermore, the results of this study may not be applicable to patients who failed other treatments. Although the incidence of drug side-effects was similar between the two antibiotics, our findings showed that gemifloxacin was not a good alternative for clarithromycin. Because of the overt usage of macrolids in Iran, the drug resistance has been increased, so this study recommended reducing the over-prescription of such antibiotics by physicians. Also, other fluoroquinolone-containing regimens such as levofloxacine or ofloxacin would be good alternatives for clarithromycin, but it should be noted that in order to avoid a further rapid increase in $H$. pylori resistance to such alternative antibiotics, the usage of quinolones-based regimens should be confined to rescue therapy only.

\section{ACKNOWLEDGEMENTS}

We would like to thank all members of Gastrointestinal \& Liver Diseases Research Center (GLDRC). Also, we would like to thank all the hospital staff that assisted us in this study.

\section{CONFLICT OF INTEREST}

The authors declare no conflict of interest related to this work.

\section{REFERENCES}

1. Goh K-L, Chan W-K, Shiota S, Yamaoka Y. Epidemiology of Helicobacter pylori Infection and Public Health Implications.Helicobacter 2011;16:1-9. doi:10.1111/j.15235378.2011.00874.x.

2. Franceschi F, Zuccala G, Roccarina D, Gasbarrini A. Clinical effects of Helicobacter pylori outside the stomach. Nat Rev Gastroenterol Hepatol 2014;11:234-42. doi: 10.1038/nrgastro.2013.243.

3. Mansour-Ghanaei F, Joukar F, Naghipour MR, Forouhari A, Seyed Saadat SM. Seven-day quintuple regimen as a rescue therapy for Helicobacter pylori eradication. World J Gastroenterol 2015;21:661-6. doi: 10.3748/wjg.v21.i2.661.

4. Ford AC, Delaney BC, Forman D, Moayyedi P. Eradication therapy for peptic ulcer disease in Helicobacter $p y$ lori positive patients. Cochrane Database Syst Rev 2016; 2:CD003840. doi:10.1002/14651858.CD003840.pub2.

5. Zullo A, Hassan C, Cristofari F, Andriani A, De Francesco V, Lerardi E, et al. Effects of Helicobacter pylori eradication on early stage gastric mucosa-associated lymphoid tissue lymphoma. Clin Gastroenterol Hepatol 2010;8:105-10. doi: 10.1016/j.cgh.2009.07.017.

6. Ma JL, Zhang L, Brown LM, Li JY, Shen L, Pan KF, et al. Fifteen-year effects of Helicobacter pylori, garlic, and vitamin treatments on gastric cancer incidence and mortality. J Natl Cancer Inst 2012;104:488-92. doi: 10.1093/ jnci/djs003.

7. Malfertheiner P, Megraud F, O'Morain CA, Atherton J, Axon AT, Bazzoli F, et al. Management of Helicobacter pylori infection - the Maastricht IV/Florence Consensus Report. Gut 2012;61:646-4. doi:10.1136/gutjnl-2012-302084.

8. Graham DY, Fischbach L. Helicobacter pylori treatment in the era of increasing antibiotic resistance. Gut 2010;59:1143-53. doi:10.1136/gut.2009.192757.

9. Graham DY, Shiotani A. Newer concepts regarding resistance in the treatment Helicobacter pylori infections. Nat Clin Pract Gasteroentrol Hepatol 2008;5:321-31. doi: 10.1038/ncpgasthep 1138 .

10. Camargo MC, Garcia A, Riquelme A, Otero W, Carmago CA, Hernandez-Garcia T, et al. The problem of Helicobacter pylori resistance to antibiotics: a systemic review. Am J Gastroenterol 2014;109:485-95. doi:10.1038/ajg.2014.24.

11. Farshad S, Alborzi A, Japoni A, Ranjbar R, Hosseini ASI K, Badiee P. et al. Antimicrobial susceptibility of Helicobacter pylori strains isolated from patients in Shiraz, Southern Iran. World J Gastroenterol 2010;16:5746-751. doi: 10.3748/wjg.v16.i45.5746.

12. Abadi AT, Taghavi T, Mobarez AM, Carpenter BM. Frequency of antibiotic resistance in Helicobacter pylori 
strains isolated from the northern population of Iran. $J \mathrm{Mi}$ crobio 2011;49:987-93. doi: 10.1007/s12275-011-1170-6.

13. Ashtari S, Pourhoseingholi MA, Molaei M, Taslimi H, Zali MR. The prevalence of Helicobacter pylori is decreasing in Iranian patients. Gasteroentrol Hepatol Bed Bench 2015;8(Suppl 1):23-9.

14. Mark C. Henderson, Lawrence M. Tierney Jr., Gerald W. Smetana. The Patient History: An Evidence-Based Approach to Differential Diagnosis. Chapter 34. Dyspepsia .McGraw-Hill; 2012.

15. Chuah SK, Tsay FW, Hsu PI, Wu DC. A new look at antiHelicobacter pylori therapy. World J Gastroenterol 2011; 17:3971-75. doi: 10.3748/wjg.v17.i35.3971.

16. Chuah SK, Hsu PI, Chang KC, Chiu YC, Wu KL, Chou $\mathrm{YP}$, et al. Randomized comparison of two non-bismuthcontaining second-line rescue therapies for Helicobacter pylori. Helicobacter 2012;17:216-23. doi: 10.1111/j.15235378.2012.00937.x.

17. Chuah SK, Tai WC, Lee CH, Liang CM, Hu TH. Quinolone containing therapies in the eradication of Helicobacter pylori. Biomed Res Int 2014;2014:151543. doi: $10.1155 / 2014 / 151543$.

18. Fakheri H, Malekzadeh R, Merat S, Khatibian M, Fazel A, Alizadeh BZ, Massarrat S. Clarithromycin vs. furazolidone in quadruple therapy regimens for the treatment of Helicobacter pylori in a population with a high metronidazole resistance rate. Aliment Pharmacol Ther 2001; 15:411-6. doi: 10.1046/j.1365-2036.2001.00931.x.

19. Le TP, Xiang YQ. Gemifloxacin; Drugs Todays (Barc) 2001;37:401-10. doi: 10.1358/dot.2001.37.6.627959.

20. Amitabh V, Singhal A,Kumar S, Patel N, Rizvi YS, Mishra P. Efficacy and safety of oral Gemifloxacin for the empirical treatment of Pneumonia. Lung India 2012;29:248-53. doi:10.4103/0970-2113.99109.

21. Sethi S, Fogarty C, Fulambarker A. A randomized, double-blined study comparing 5 days oral Gemifloxacin with 7 days oral Levofloxacin in patients with acute exacerbations of chronic bronchitis. Respir Med 2008; 98:697-707. doi: 10.1016/j.rmed.2004.03.028.

22. Wilson R, Schentag JJ, Ball P, Mandell L. A comparison of Gemifloxacin and Clarithromycin in acute exacerbations of chronic bronchitis and long-term clinical outcomes. Clin Ther 2004;24:639-52. doi:10.1016/S01492918(02)85139-6.

23. Yang JC, Lec PI, Hsueh PR. In vitro activity of nemonoxacin, tigecycline, and other antimicrobial agents against Helicobacter pylori isolates in Taiwan, 1998-2007. Eur J Clin Microbiol Infect Dis 2010;29:1369-75. doi: 10.1007/ s10096-010-1009-9.

24. Minakari M, Davarpanah Jazi AH, Shavakhi A, Moghareabed N, Fatahi F. A randomized controlled trial: Efficacy and safety of azithromycin, ofloxacin, bismuth, and omeprazole compared with amoxicillin, clarithromycin, bismuth, and omeprazole as second-line therapy in patients with Helicobacter pylori infection. Helicobacter
2010;15:154-9. doi: 10.1111/j.1523-5378.2009.00739.x.

25. Nasa M, Choksey A, Phadke A, Sawant P. Sequential therapy versus standard triple-drug therapy for Helicobacter pylori eradication: A randomized study. Indian J Gastroenterol 2013;32:392-6. doi: 10.1007/s12664-013-0357-7.

26. Chang WL, Kao CY, Huang AH, Wu JJ,Yang HB, Cheng $\mathrm{HC}$, et al. Gemifloxacin can partially overcome quinolone resistance of H.pylori with gyrA mutation in Taiwan. Helicobacter 2012;17:210-15. doi: 10.1111/j.15235378.2012.00935.x.

27. Masoodi M, Talebi-Taher M, Tabatabaie KH, Khaleghi S, Faghihi AH, Agah SH, et al. Clarithromycin vs. Gemifloxacin in Quadruple Therapy Regimens for Empiric Primary Treatment of Helicobacter pylori Infection: A Randomized Clinical Trial. Middle East J Dig Dis 2015;7:88-93.

28. Minehart HW, Chalker AF. In vitro Activity of Gemifloxacin against Helicobacter pylori. J Antimicrob Chemother 2001;47:360-1. doi:10.1093/jac/47.3.360.

29. Mahmoudi L, Farshad S, Seddigh M, Mahmoudi P, Ejtehadi F, Niknam R. High efficacy of gemifloxacin-containing therapy in Helicobacter Pylori eradication: A pilot empirical second-line rescue therapy. Medicine (Baltimore) 2016;95:e4410. doi:10.1097/MD.0000000000004410.

30. Malfertheiner P, Megraud F, O'Morain CA, Gisbert JP, Kuipers EJ, Axon AT, et al. Management of Helicobacter pylori infection the Maastricht V/Florence Consensus Report. Gut 2017;66:6-30. doi: 10.1136/gutjnl-2016-312288. 